\title{
Persepsi Orangtua terhadap Pelaksanaan Belajar dari Rumah pada Pendidikan Anak Usia Dini
}

\author{
Oktarina Dwi Handayani $1^{\text {凶 }}$ \\ Pendidikan Guru Pendidikan Anak Usia Dini, Universitas Muhammadiyah Prof. Dr. \\ HAMKA \\ DOI: $10.31004 /$ obsesi.v5i2.975
}

\begin{abstract}
Abstrak
Pandemi Covid-19 membawa dampak perubahan pada pelaksanaan pendidikan yang sedianya dilakukan secara tatap muka, disesuaikan melalui kegiatan Belajar dari Rumah (BDR). Pelaksanaan BDR yang tidak direncanakan sebelumnya oleh pendidik, peserta didik dan orang tua mendatangkan berbagai tantangan. Oleh karena itu peneliti hendak melihat persepsi orang tua terhadap pelaksanaan BDR pada anak usia 5-6 tahun pada PAUD di kota Bekasi. Kegiatan penelitian ini menggunakan metode penelitian kuantitatif dengan menggunakan kuesioner yang sudah tervalidasi selanjutnya melaksanakan penghimpunan data melalui google form. Data yang telah dihimpun diolah menggunakan program SPSS dengan analisis data chi square untuk melihat hubungan antara variabel X dan Y. Dari hasil penelitian yang dilaksanakan didapatkan hasil bahwa pelaksanaan BDR pada PAUD di kota Bekasi mendapatkan persepsi positif dari orang tua dipengaruhi oleh faktor; perencanaan pembelajaran yang disusun, media dan bahan ajar yang digunakan serta penilaian yang dilaksanakan oleh pendidik. Melalui penelitian ini memberikan gambaran bahwa pelaksanaan BDR pada PAUD dipengaruhi oleh kesiapan dan sumber daya yang dimiliki oleh lembaga PAUD, peserta didik dan orang tua murid.
\end{abstract}

Kata Kunci: pendidikan anak usia dini; orang tua; belajar dari rumah

\begin{abstract}
The Covid-19 pandemic has had a changing impact on the implementation of education which was originally carried out face-to-face, adjusted through Learning from Home (BDR) activities. The implementation of BDR that was not planned by educators, students, and parents presented various challenges. Therefore, the researcher wanted to see the parents' perceptions of the implementation of BDR in children aged 5-6 years at PAUD in Bekasi city. This research activity uses quantitative research methods using a validated questionnaire then carry out data collection via a google form. The data that has been collected is processed using the SPSS program with chi-square data analysis to see the relationship between $X$ and $Y$ variables. From the results of the research carried out, it is found that the implementation of BDR in early childhood education in Bekasi city gets positive perceptions from parents influenced by factors; lesson plans are prepared, the media and teaching materials used and the assessments carried out by educators. This research illustrates that the implementation of BDR in early childhood education is influenced by the readiness and resources of the PAUD institutions, students, and parents.
\end{abstract}

Keywords: home; learning, parental perceptions, early childhood education

Copyright (c) 2021 Oktarina Dwi Handayani

$\triangle$ Corresponding author:

Email Address: oktarina2h@uhamka.ac.id (Jakarta, Indonesia)

Received 23 December 2020, Accepted 31 December 2020, Published 9 Januari 2021

1754 | Jurnal Obsesi: Jurnal Pendidikan Anak Usia Dini, 5(2), 2021 


\section{PENDAHULUAN}

Pandemi COVID-19 berdampak pada berbagai sektor kehidupan seperti ekonomi, sosial, termasuk pendidikan (Bersama Hadapi Korona, n.d.). Pemerintah mengambil langkah mengganti proses pembelajaran tatap muka di sekolah menjadi kegiatan pembelajaran dari rumah (home learning). Kegiatan belajar dari rumah menekankan pada kegiatan pembelajaran dalam jaringan (daring) / jarak jauh (distance learning) yang dilaksanakan guna memberikan pengalaman belajar yang bermakna bagi peserta didik (Kementerian Ristekdikti, 2016). Kegiatan distance learning diatur dalam undang UU No.12/2012 disebutkan bahwa proses pendidikan jarak jauh menjembatani keterpisahan antara peserta didik dengan pendidik dan dimediasi oleh pemanfaatan teknologi, dan pertemuan tatap muka yang minimal. Pendidikan jarak jauh ditawarkan lintas ruang dan waktu sehingga siswa memperoleh fleksibilitas belajar dalam waktu dan tempat yang berbeda, serta menggunakan beragam sumber belajar (Kementrian Riset Teknologi dan PendidikanTinggi, 2016). Pemberlakuan kebijakan distance learning juga diaplikasikan pada layanan pendidikan anak usia dini (PAUD). Pendidikan pada anak usia dini diperuntukkan bagi anak usia 0-6 tahun menyumbang $90 \%$ dari semua perkembangan otak manusia oleh karena itu masa ini disebut masa emas (golden period) (Harper \& Wilson, 2020). Pembelajaran PAUD menerapkan kegiatan bermain sembari belajar yang bertujuan untuk membangun landasan bagi berkembangnya potensi anak agar menjadi manusia beriman dan bertaqwa kepada Tuhan Yang Maha Esa, berakhlak mulia, sehat, berilmu, cakap, kritis, kreatif, inovatif, mandiri, percaya diri dan menjadi warga negara yang demokratis dan bertanggung jawab (Barat, 2017).

Pelaksanaan BDR pada PAUD menemukan tantangannya tersendiri karena anak usia dini belum mampu melaksanakan kegiatan pembelajarannya secara mandiri yaitu membutuhkan dukungan dan bantuan dari orang dewasa di sekitarnya dalam hal ini adalah orang tua. Peran orang tua dalam pendidikan anak usia dini adalah mengkondisikan lingkungan keluarga dengan menjadikan rumah sebagai tempat yang nyaman untuk menunjang pendidikan anak (Wijayanti et al., 2021). Berdasarkan hasil observasi yang dilaksanakan melalui studi pendahuluan, kegiatan belajar dari rumah orang tua berperan sebagai perantara, pengantar pesan dari pendidik ke peserta didik, karena anak usia dini belum mampu melaksanakan pembelajaran daring secara mandiri. Selain itu orang tua dituntut untuk menggantikan peran pendidik dalam kegiatan pembelajaran sebagai fasilitator dan motivator bagi peserta didik dalam melaksanakan Distance Learning (Covid- et al., 2020). Problematik dari kegiatan pembelajaran dari rumah yang dilaksanakan di PAUD adalah peserta didik belum mampu melaksanakan kegiatan pembelajaran secara mandiri atau membutuhkan pendampingan dari orang dewasa di sekitarnya. Hal ini tentunya menjadi kendala karena rumah orang tua harus memberikan pendampingan kepada anak sembari melaksanakan kewajiban bekerja dari rumah (work from home). Jadi pada kegiatan belajar dari rumah orang tua dan pendidik PAUD dituntut agar dapat berkolaborasi dalam menghadirkan kegiatan pembelajaran pada anak. Orang tua harus mampu menerjemahkan pesan yang diberikan oleh pendidik untuk selanjutnya dapat diimplementasikan di rumah (Hakim, 2020).

Media pembelajaran yang digunakan pada PAUD dengan mempergunakan barangbarang yang ada di sekitar anak sehingga kegiatan yang dilaksanakan menjadi bermakna (Zaini \& Dewi, 2017). Pada kegiatan pembelajaran tema yang disusun pada PAUD disesuaikan dengan kehidupan di sekitar anak, seperti teori kognitif yang dikemukakan oleh Jean Piaget bahwa anak belajar dari hal-hal nyata yang berasal dari lingkungan di sekitarnya. Melalui aktivitas belajar dari rumah, pendidik PAUD dituntut untuk dapat menghadirkan pendidikan yang memiliki muatan pembelajaran yang mampu menstimulasi kemampuan berpikir tingkat tinggi pada anak (HOTS) pembelajaran HOTS mengedepan kegiatan belajar dengan mengutamakan prinsip pemecahan masalah dengan menggali berbagai ide, gagasan, pendapat serta pembelajaran yang melalui kegiatan pembelajaran yang diselenggarakan (Heong et al., 2016). Kegiatan pembelajaran HOTS pada PAUD tercermin 
dalam perangkat pembelajaran (perencanaan, media dan bahan ajar serta instrumen evaluasi) dan pelaksanaan pembelajaran. Misalkan, ketika membahas tema alat transportasi Kereta Api, pendidik tidak hanya menjelaskan mengenai bentuk Kereta namun pembelajaran yang dilaksanakan harus dirancang secara mendalam seperti menyebutkan jenis-jenis, sejarah, bagian, cara membeli tiket, kegunaan dan manfaat, tata tertib dalam menggunakan transportasi Kereta Api, hingga kepada kunjungan lapangan untuk melihat secara langsung sebagai bentuk implementasi pembelajaran operasional konkret kepada anak. Pembelajaran HOTS pada PAUD dibangun sebagai bentuk stimulasi yang diberikan kepada anak sehingga anak dapat melaksanakan pembelajaran secara mendalam tidak hanya berada pada bagian kulit luarnya saja.

Pembelajaran HOTS membutuhkan dukungan Technological Pedagogical Content Knowledge (TPACK) yang berarti bahwa untuk menciptakan pembelajaran yang efektif dengan menggunakan dukungan penggunaan teknologi di dalam pembelajaran (Blackwell et al., 2016). Kegiatan pembelajaran dari rumah mempergunakan dukungan pembelajaran dalam jaringan melalui teknik sinkron atau asinkron (Singh \& Thurman, 2019) sehingga memungkinkan peserta didik terlibat interaksi dengan pendidik. Pada kegiatan BDR pada PAUD penggunaan TPACK tercermin di dalam penggunaan media dan bahan ajar dengan memanfaatkan dukungan teknologi seperti penggunaan PPT dan video pembelajaran yang disesuaikan dengan tema. Selain itu bentuk implementasi TPACK pada pelaksanaan BDR PAUD dengan menggunakan berbagai aplikasi diantaranya adalah; Zoom, Whatsapp, Youtube, Google Meet, Microsoft Teams.

Berdasarkan berbagai referensi yang telah dikaji oleh peneliti membahas mengenai pelaksanaan BDR pada PAUD namun lebih banyak mengkaji mengenai bentuk pelaksanaan dan kegiatan yang dilaksanakan. Pada penelitian ini peneliti hendak mengkaji mengenai persepsi orang tua mengenai pelaksanaan BDR hal ini didasarkan karena orang tua yang menjadi jembatan sekaligus penerjemah informasi pembelajaran yang diberikan oleh pendidik kepada peserta didik. Terdapat 1636 lembaga PAUD di kota Bekasi (Kemendikbud, 2020) yang pada pandemi Covid-19 melaksanakan kegiatan BDR sesuai dengan Surat Edaran (SE) Mendikbud Nomor 4 Tahun 2020 yang berisi pelaksanaan pendidikan dalam masa darurat Pandemi Covid-19. Dari hasil penelitian dihimpun diharapkan dapat dijadikan gambaran mengenai persepsi orang tua terhadap pelaksanaan BDR pada PAUD di kota Bekasi sehingga dapat digunakan sebagai salah satu masukan dalam pengembangan pelaksanaan BDR pada PAUD di masa mendatang.

\section{METODOLOGI}

Penelitian ini menggunakan metodologi kuantitatif deskriptif dengan metode Survei. Metode Survei digunakan untuk mengumpulkan informasi dalam bentuk opini dari berbagai topik atau isu-isu dari sejumlah besar orang atau masyarakat (Hamdi \& E.Bahruddin, 2012). Melalui penelitian survei memungkinkan peneliti menjawab pertanyaan mengenai persepsi dan praktik dalam populasi tertentu (Kelley-Quon, 2018). Melalui penelitian survei yang dilaksanakan hendak melihat persepsi yang dihimpun dari orang tua atau wali murid mengenai efektivitas pelaksanaan BDR pada PAUD berdasarkan persepsi orang tua di kota Bekasi. Penelitian ini mengambil sampel orang tua atau wali murid dari anak usia 5-6 tahun pada lembaga PAUD di Kota Bekasi yang terdistribusi kepada 8 lembaga PAUD di wilayah kota Bekasi. Teknik pengumpulan data menggunakan kuesioner melalui media google form yang didistribusikan dengan dengan menggunakan whatsapp sehingga terkumpul data penelitian sejumlah 150 responden. Alur penelitian yang dilaksanakan dapat dilihat melalui gambar 1.

Kegiatan penelitian dilaksanakan melalui studi pendahuluan mengenai pelaksanaan BDR pada PAUD di kota Bekasi, berdasarkan hasil studi pendahuluan yang dihimpun kemudian peneliti melaksanakan rumusan kegiatan penelitian disertai dengan menghimpun kajian pustaka yang relevan. Dari hasil kajian pustaka peneliti merumuskan instrumen 
penelitian yang digunakan sebagai alat untuk menghimpun data lapangan. Sebelum melaksanakan kegiatan pengumpulan data peneliti melaksanakan validitas instrumen penelitian yang bertujuan untuk mengukur keabsahan instrumen sebelum digunakan sebagai alat dalam mengumpulkan data penelitian. Uji validitas dilakukan terhadap responden yang memenuhi kriteria yang telah ditentukan, pada uji validitas instrumen peneliti melaksanakan uji instrumen kepada 65 responden untuk memperoleh instrumen yang dinyatakan valid dari hasil uji instrumen data diolah menggunakan teknis analisis SPSS sehingga didapatkan pernyataan dinyatakan valid apabila $\mathrm{r}$ hitung $>\mathrm{r}$ tabel. Kuesioner di dalam penelitian menggunakan skala Likert untuk mengetahui persepsi responden terhadap pelaksanaan belajar dari rumah pada PAUD. Teknis analisis data yang digunakan dengan menggunakan analisis Bivariat digunakan untuk mengasumsikan dua variabel yang berkorelasi atau memiliki hubungan (Manju et al., 2020). Uji statistik yang digunakan dalam penelitian ini adalah Chi Square, tujuan dari analisis ini adalah untuk mengetahui hubungan antara variabel $X$ dengan variabel $Y$.

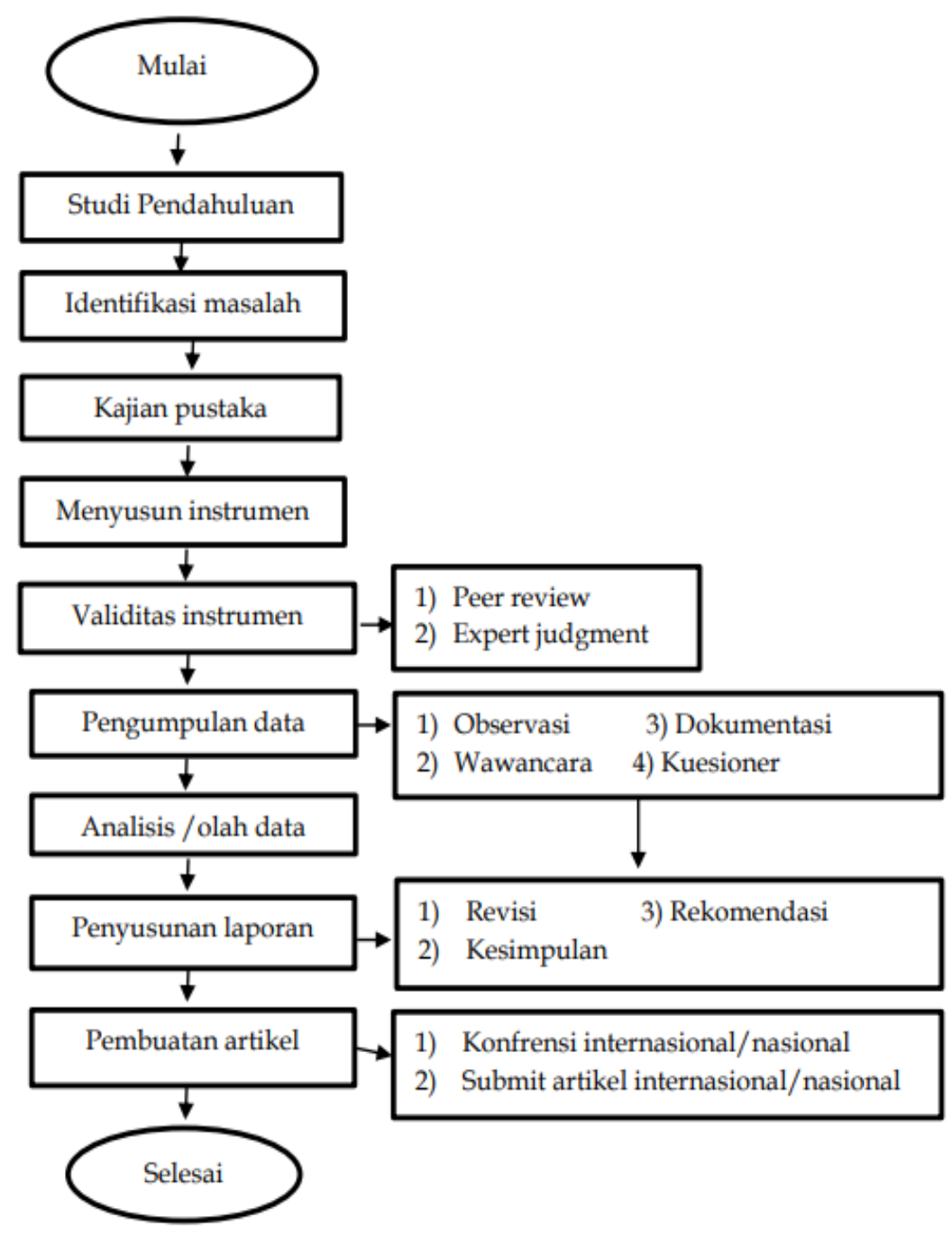

Gambar 1; Bagan Alur Penelitian

\section{HASIL DAN PEMBAHASAN}

Menganalisis Persepsi Orangtua mengenai Perencanaan Pembelajaran terhadap Pelaksanaan BDR pada PAUD

Berdasarkan hasil kuesioner didapatkan data bahwa, hasil uji statistik dengan menggunakan Chi Square diperoleh nilai $\mathrm{P}=0,000$ diartikan bahwa $\mathrm{P}<0,005$ maka Ho ditolak jadi terdapat hubungan antara perencanaan pembelajaran yang dibuat oleh guru terhadap 
pelaksanaan belajar dari rumah pada PAUD di kota Bekasi. Nilai Chi Square hitung >chi square tabel yaitu; 24,161 > 3,841 sehingga sehingga diartikan bahwa ada hubungan antara perencanaan pada pembelajaran PAUD terhadap pelaksnaan BDR pada lembaga PAUD di kota Bekasi. Untuk mengetahui keeratan hubungan antara perencanaan yang dilakukan oleh pendidik terhadap pelaksanaan BDR pada PAUD diperoleh nilai $r=0,401$ termasuk pada kategori cukup. Selengkapnya dapat dilihat pada tabel 1.

Tabel 1; Hasil Perhitungan antara Variabel Perencanaan Pembelajaran terhadap Pelaksanaan BDR

\begin{tabular}{|c|c|c|c|c|c|}
\hline & Value & $\mathrm{df}$ & $\begin{array}{c}\text { Asymptotic } \\
\text { Significance (2-sided) }\end{array}$ & $\begin{array}{l}\text { Exact Sig. } \\
\text { (2-sided) }\end{array}$ & $\begin{array}{l}\text { Exact Sig. } \\
\text { (1-sided) }\end{array}$ \\
\hline Pearson Chi-Square & $24,161^{a}$ & 1 & 000 & \multirow{6}{*}{,040 } & \multirow{6}{*}{,040 } \\
\hline Continuity Correction ${ }^{b}$ & 5,547 & 1 & 019 & & \\
\hline Likelihood Ratio & 6,608 & 1 & 010 & & \\
\hline Fisher's Exact Test & & & & & \\
\hline Linear-by-Linear Association & 24,000 & 1 & ,000 & & \\
\hline $\mathrm{N}$ of Valid Cases & 150 & & & & \\
\hline
\end{tabular}

Perencanaan pembelajaran memegang peranan penting dalam kesuksesan pelaksaan pembelajaran hal ini didukung sejalan dengan hasil penelitian mengenai; "Peran perencanaan pembelajaran untuk performance mengajar guru pendidikan anak usia dini; kegiatan pembelajaran PAUD dilaksanakan melalui setting kegiatan main didesain melalui rencana pelaksanaan pembelajaran (RPH) yang dibuat bulanan melalui tema, minggu dan harian. Rencana pelaksanaan pembelajaran harian (RPPH) memberikan panduan bagi guru dalam melaksanakan kegiatan main harian agar tercapai tujuan dalam pembelajaran (Sufiati \& Afifah, 2019). Oleh karena itu, diperlukan perencanaan pembelajaran yang baik agar pelaksanaan pembelajaran berjalan dengan baik. Jadi pendidik berperan sebagai perancang pembelajaran sekaligus sebagai pengelola serta pelaksana pembelajaran (Dewi \& Primayana, 2019). Berdasarkan penelitian didapatkan hasil bahwa berdasarkan persepsi orang perencanaan pembelajaran yang didesain oleh pendidik memiliki pengaruh pada pelaksanaan BDR pada PAUD. Berdasarkan hasil survei yang dilaksanakan rancangan BDR yang dibuat pendidik berisi informasi yang diberikan mengenai perubahan metode pembelajaran dari luar jaringan (luring) menjadi dalam jaringan (daring), sarana dan prasarana yang harus dipersiapkan oleh orang tua, jadwal pelaksanaan pembelajaran, tema pembelajaran serta panduan dalam memberikan pendampingan BDR.

Selain itu rancangan pembelajaran yang disampaikan oleh pendidik mempergunakan media komunikasi daring yang mudah diakses sehingga memudahkan orang tua dalam mengakses informasi yang diberikan. Selain itu, berdasarkan persepsi orang tua rancangan BDR yang diberikan memuat aspek perkembangan anak yang tertuang ke dalam BDR yang diimplementasikan ke dalam kehidupan keseharian peserta didik. Rancangan yang dibuat oleh pendidik harus memperhatikan aspek perkembangan anak, sehingga kegiatan pembelajaran yang disajikan merupakan yang terdekat dengan kehidupan anak. Oleh karena itu PAUD merupakan pendidikan yang melandaskan kegiatannya pembelajarannya terhadap kepekaan lingkungan serta minat yang dimiliki anak (Ardoin \& Bowers, 2020).

Perencanaan pembelajaran pada PAUD dimasa Pandemi ini berorientasi pada penanaman kecakapan hidup (lifeskills) pada anak, jadi pelaksanaan BDR tidak hanya berfokus kepada capaian kurikulum tetapi mengedepankan pengalaman belajar yang bermakna melalui implementasi aktivitas keseharian anak (Hewi \& Asnawati, 2020). Berdasarkan hasil penelitian yang dilakukan bahwa pada pelaksanaan BDR PAUD diperlukan perencanaan pembelajaran yang baik karena kegiatan pembelajaran yang seyogyanya 
diberikan oleh pendidik, mengalami perubahan dengan kegiatan pembelajaran dilaksanakan oleh orang tua bersama peserta didik di rumah. Oleh karena itu perencanaan pembelajaran juga harus disesuaikan dengan kondisi BDR yaitu tidak hanya sekedar memberikan informasi mengenai jadwal pembelajaran namun perlu disampaikan mengenai sarana dan prasarana serta pedoman mengenai teknis dan tata cara penyelenggaraan BDR, hal ini bertujuan agar kegiatan BDR berjalan dengan optimal. Pelaksanaan BDR menjadi hal baru bagi PAUD oleh karena itu melalui kegiatan penelitian mengkaji persepsi orang tua terkait pelaksanaan BDR.

\section{Menganalisis Persepsi Orang Tua pada Penggunaan Media dan Bahan Ajar terhadap Pelaksanaan BDR pada PAUD}

Berdasarkan data penelitian yang dihimpun mengenai persepsi orang tua pada media dan bahan ajar yang digunakan terhadap pelaksanaan BDR pada PAUD di kota Bekasi didapatkan hasil bahwa; Karena nilai Asymptotic Significance 0,000 $<0,05$ dan pada output "Chi-Square test" diketahui bahwa; Nilai Chi Square hitung >chi square tabel yaitu; 74,497 > 3,841 diartikan bahwa ada media dan materi yang dirancang oleh guru terhadap pelaksnaan BDR pada lembaga PAUD di kota Bekasi maka dapat disimpulkan bahwa terdapat hubungan yang signifikan antara media dan bahan ajar yang dirancang oleh guru terhadap pelaksnaan BDR pada lembaga PAUD. Sedangkan keeratan hubungan ditunjukkan $r=0,705$ yang berarti keeratan antara variabel persepsi orang tua mengenai penggunaan media dan bahan ajar yang didesain oleh guru terhadap pelaksanaan BDR adalah kuat, digambarkan melalui tabel 2.

Tabel 2; Hasil Perhitungan antara Variabel Persepsi Orangtua pada Media dan Bahan Ajar terhadap Pelaksanaan BDR

\begin{tabular}{|c|c|c|c|c|c|}
\hline & Value & $\mathrm{df}$ & $\begin{array}{l}\text { Asymptotic Significance (2- } \\
\text { sided) }\end{array}$ & $\begin{array}{l}\text { Exact Sig. } \\
\text { (2-sided) }\end{array}$ & $\begin{array}{l}\text { Exact Sig. (1- } \\
\text { sided) }\end{array}$ \\
\hline Pearson Chi-Square & $74,497^{a}$ & 1 & , 000 & \multirow{7}{*}{ 013 } & \multirow{7}{*}{ 013 } \\
\hline Continuity Correction ${ }^{b}$ & 18,124 & 1 & ,000 & & \\
\hline Likelihood Ratio & 9,242 & 1 & ,002 & & \\
\hline Fisher's Exact Test & & & & & \\
\hline Linear-by-Linear & 74,000 & 1 &, 000 & & \\
\hline Association & & & & & \\
\hline $\mathrm{N}$ of Valid Cases & 150 & & & & \\
\hline
\end{tabular}

Media pembelajaran memegang peran penting dalam pelaksanaan PAUD sebagai alat main edukatif yang mampu menstimulasi aspek perkembangan anak (Handayani, 2020). Gagne (1970) mendefinisikan media pembelajaran sebagai komponen yang digunakan peserta didik dalam menerima pesan yang diberikan oleh pendidik. Penggunaan media pembelajaran yang tepat merupakan sarana stimulasi aspek perkembangan anak, mengutip hasil penelitian; "penggunaan media buku pop up dalam menstimulasi aspek perkembangan kognitif pada anak usia 4-5 tahun". Dari hasil penelitian tersebut dinyatakan bahwa; media buku pop-up layak digunakan untuk anak usia 4-5 tahun, ditunjukkan melalui peningkatan hasil belajar peserta didik dengan hasil 89\% dan 98,06\% dengan kriteria sangat baik, setelah menggunakan media buku pop-up (Rahmawati \& Rukiyati, 2018). Berdasarkan hasil penelitian yang dilaksanakan mengenai persepsi orang tua terhadap media dan bahan ajar yang digunakan terhadap pelaksanaan BDR didapatkan hasil bahwa; media dan bahan ajar yang digunakan oleh pendidik memiliki pengaruh positif dalam pelaksanaan BDR pada PAUD di kota Bekasi. Pembelajaran dari rumah (BDR) peserta didik PAUD menggunakan media pembelajaran digital, teknologi dan media interaktif yang berfungsi sebagai media pembelajaran (Donohue, 2014) oleh karena itu penggunaan media dan bahan ajar yang sesuai dan relevan merupakan salah satu faktor yang perlu diperhatikan oleh pendidik dalam pelaksanaan BDR. 
Pada pelaksanaan BDR PAUD penggunaan TPACK diintegrasikan pada media pembelajaran dan bahan ajar, berdasarkan data penelitian yang dihimpun media dan bahan ajar yang digunakan di antaranya adalah; presentasi dan video pembelajaran yang di upload laman media sosial lembaga melalui berbagai platform yang kemudian digunakan bahan ajar, teknologi komunikasi dengan berbagai platform yaitu; whatsapp, zoom, google meet, dan google form. Selain itu pada pelaksanaan BDR, penggunaan media sebagai sumber belajar memanfaatkan barang-barang yang ada di sekitar anak disesuaikan dengan tema dan materi pembelajaran yang diangkat. Misalkan pada tema lingkunganku, anak menggunakan berbagai media yang ada di lingkungan rumahnya didukung dengan bahan ajar yang diberikan oleh pendidik melalui platform yang telah ditentukan dalam bentuk video pembelajaran maupun presentasi materi sehingga orang tua sebagai mediator mampu menerjemahkan pesan pembelajaran yang diberikan oleh pendidik. Berdasarkan data tersebut media dan bahan ajar yang digunakan pada BDR memiliki pengaruh positif terhadap pelaksanaan BDR. Oleh karena itu melalui penelitian ini memberikan gambaran mengenai penggunaan media dan bahan ajar yang digunakan dalam BDR. Pendidik perlu melakukan inovasi pada media dan bahan ajar yang digunakan sesuai dengan konteks situasi dan kondisi pembelajaran. Oleh karena itu pendidik dituntut untuk mengintegrasikan pembelajaran dengan teknologi sehingga tercipta pembelajaran yang efektif bagi peserta didik (Koehler et al., 2013).

\section{Menganalisis Persepsi Orang Tua pada Penilaian Pembelajaran (Perkembangan Anak) terhadap Pelaksanaan BDR pada PAUD}

Dari hasil kursioner yang dihimpun pada data penelitian menunjukkan nilai Asymptotic Significance 0,000 $<0,05$ dan pada tabel output "Chi-Square test" diketahui bahwa; Nilai Chi Square hitung >chi square tabel yaitu; 150,00 > 3,841 maka dapat disimpulkan bahwa terdapat hubungan yang signifikan antara penilaian yang dilaksanakan oleh guru terhadap pelaksanaan BDR pada lembaga PAUD. Sedangkan keeratan hubungan ditunjukkan $r=1,00$ yang berarti keeratan antara variabel persepsi orang tua mengenai penilaian pembelajaran yang dilaksanakan pendidik terhadap pelaksanaan BDR PAUD adalah sempurna. Selengkapnya dapat dilihat pada tabel 3.

Tabel 3; hasil perhitungan antara variabel persepsi orang tua pada Penilaian pembelajaran terhadap pelaksanaan BDR

\begin{tabular}{|c|c|c|c|c|c|}
\hline & Value & hi-Sq & $\begin{array}{l}\text { uare Tests } \\
\text { Asymptotic } \\
\text { Significance (2- } \\
\text { sided) }\end{array}$ & $\begin{array}{l}\text { Exact Sig. (2- } \\
\text { sided) }\end{array}$ & $\begin{array}{l}\text { Exact Sig. (1- } \\
\text { sided) }\end{array}$ \\
\hline Pearson Chi-Square & $150,000^{a}$ & & ,000 & & \\
\hline Continuity Correction $\mathrm{b}$ & 36,998 & & 000 & & \\
\hline Likelihood Ratio & 12,015 & & 001 & & \\
\hline Fisher's Exact Test & & & & ,007 & ,007 \\
\hline $\begin{array}{l}\text { Linear-by-Linear } \\
\text { Association }\end{array}$ & 149,000 & & ,000 & & \\
\hline $\mathrm{N}$ of Valid Cases & 150 & & & & \\
\hline
\end{tabular}

Pada pelaksanaan BDR penilaian perkembangan anak dilakukan dengan menganalisis hasil dokumentasi yang diberikan oleh orang tua kepada pendidik. Proses penilaian pada kegiatan BDR dilakukan berdasarkan hasil lembar kerja peserta didik (LKPD) yang diberikan oleh orang tua kepada pendidik. Melalui LKPD pendidik melakukan analisis kegiatan BDR yang dilakukan anak. Pelaporan LKPD dilaksanakan berdasarkan rentan waktu yang telah 
disepakati. Pada pelaksanaan BDR, LKPD menjadi bagian penting yang digunakan dalam asessment pertumbuhan dan perkembangan anak. Melalui LKPD pendidik membuat analisis perkembangan anak disesuaikan dengan standar tingkat pencapaian perkembangan anak untuk selanjutnya di rumuskan capaian perkembangan peserta didiknya. Penilaian perkembangan dibuat sebagai monitoring dan evaluasi dalam tumbuh dan kembang anak dengan menggunakan berbagai bentuk penilaian yang terdokumentasikan (Berman, 2019). Pada asessment perkembangan anak mencakup semua aspek perkembangan peserta didik, yang tertuang di dalam kompetensi peserta didik meliputi; sikap, pengetahuan, keterampilan (Zahro, 2015). Selain itu berdasarkan data hasil analisis perkembangan peserta didik, pendidik juga melaksanakan penilaian terhadap program BDR yang dilaksanakannya. Penilaian pembelajaran memiliki peran penting sebagai alat evaluasi dalam menilai kesesuaian kegiatan pembelajaran yang telah dilaksanakan dalam mendukung pembelajaran dan perkembangan anak (Nah \& Kwak, 2011). Melalui kegiatan penilaian pembelajaran yang dilaksanakan, pendidik memperoleh informasi mengenai efektivitas kegiatan pembelajaran yang dilaksanakannya. Hal ini tentunya memberikan kontribusi penting dalam pengambilan keputusan yang berkaitan dengan dukungan penyelenggaraan pelaksanaan pembelajaran (Pellegrini, 2001).

Berdasarkan hasil kuesioner yang dihimpun didapatkan hasil bahwa berdasarkan persepsi orang tua pada penilaian pembelajaran memberikan pengaruh yang positif terhadap pelaksanaan BDR pada PAUD di kota Bekasi. Melalui kegiatan penilaian pembelajaran orang tua memperoleh umpan balik mengenai perkembangan dan pertumbuhan anak selama melaksanakan kegiatan BDR serta menjadi alat evaluasi bagi pendidik dalam pelaksanaan BDR. Melalui kegiatan penelitian ini memberikan gambaran mengenai peran penilaian pembelajaran dalam pelaksanaan BDR, yaitu sebagai alat dalam memonitor tumbuh dan kembang peserta didik dan sebagai alat dalam mengevaluasi kegiatan BDR yang dilaksanakan pendidik.

Berdasarkan data penelitian yang dihimpun melalui kegiatan penelitian yang telah dilaksanakan, terdapat keterbatasan penelitian yaitu; kegiatan penelitian dilaksanakan dengan mengambil sampel dan responden penelitian pada lembaga PAUD yang terakreditasi A dan B dengan dukungan sarana dan prasarana yang memadai dalam melaksanakan BDR baik dari pihak penyelenggara pendidikan (lembaga pendidikan) maupun wali murid sehingga hasil penelitian ini tidak bisa digeneralisasikan pada lembaga PAUD lainnya yang memiliki perbedaan situasi, kondisi maupun daya dukung sarana dan prasarana. Oleh karena itu berdasarkan hasil penelitian yang dihimpun memberikan gambaran bahwa pelaksanaan BDR akan berjalan dengan baik didukung dengan perencanaan, media dan bahan ajar serta instrumen asessment perkembangan anak yang baik selain itu faktor daya dukung sarana dan prasarana yang dimiliki oleh lembaga dan peserta didik menjadi faktor yang krusial dalam pelaksanaan BDR. Berdasarkan informasi di atas penelitian ini perlu dilaksanakan tindak lanjut dengan mengambil responden pada lembaga PAUD lain yang berbeda karakteristik sehingga didapatkan gambaran yang lebih komprehensif.

\section{SIMPULAN}

Berdasarkan hasil temuan penelitian didapatkan data bahwa orang tua murid dari anak usia 5-6 tahun pada lembaga PAUD di kota Bekasi memiliki persepsi positif terhadap pelaksanaan BDR. Melalui hasil penelitian ini memberikan gambaran bahwa pelaksanaan BDR dapat terlaksana dengan efektif melalui dukungan sarana, prasarana dari lembaga penyelenggara pendidikan maupun orang tua murid. Berdasarkan persepsi orang tua pelaksanaan BDR dapat berjalan dengan baik melalui perencanaan pembelajaran, materi dan bahan ajar serta asessment yang dilaksanakan pada BDR. 


\section{UCAPAN TERIMA KASIH}

Puji syukur penulis panjatkan kehadirat Alloh SWT sehingga pelaksanaan penelitian dapat terlaksana dengan baik. Ucapan terima kasih penulis sampaikan kepada keluarga atas dukungan dan motivasi serta lembaga penelitian dan pengembangan (Lemlitbang) UHAMKA yang telah memberikan fasilitas kepada penulis dalam pelaksanaan riset serta publikasi. Penulis menghaturkan terima kasih kepada PAUD di kota Bekasi yang bersedia membantu penulis dalam menghimpun data penelitian serta kepada tim Jurnal Obsesi: Jurnal Pendidikan Anak Usia Dini yang berkenan untuk menerima hasil luaran artikel kegiatan penelitian yang dilaksanakan.

\section{DAFTAR PUSTAKA}

Ardoin, N. M., \& Bowers, A. W. (2020). Early childhood environmental education: A systematic review of the research literature. In Educational Research Review (Vol. 31, Nomor November 2019, hal. 100353). Elsevier Ltd. https:// doi.org/10.1016/j.edurev.2020.100353

Barat, P.-P. dan D. J. (2017). Modul konsep dasar pendidikan anak usia dini. Kementerian Pendidikan dan Kebudayaan Direktorat Jenderal Pendidikan Anak Usia Dini dan Pendidikan Masyarakat PP-PAUD dan Dikmas Jawa Barat.

Berman, N. M. (2019). Developmentally Appropriate Communication. In A Guide to Mastery in Clinical Nursing. https:/ / doi.org/10.1891/9780826150325.0257

Bersama Hadapi Korona. (n.d.). Kementerian Pendidikan dan Kebudayaan. https:/ / bersamahadapikorona.kemdikbud.go.id/

Blackwell, C. K., Lauricella, A. R., \& Wartella, E. (2016). The influence of TPACK contextual factors on early childhood educators' tablet computer use. Computers and Education, 98, 57-69. https://doi.org/10.1016/j.compedu.2016.02.010

Covid-, T., Speech, H., Citizenship, D., \& Response, E. (2020). COVID-19 Education Response Webinar. July, 1-4.

Dewi, P. Y. A., \& Primayana, K. H. (2019). Effect of Learning Module with Setting Contextual Teaching and Learning to Increase the Understanding of Concepts. International Journal of Education and Learning, 1(1), 19-26. https:/ / doi.org/10.31763/ijele.v1i1.26

Donohue, C. (2014). Technology and Digital Media in the Early Years: Tools for Teaching and Learning. A Co-Publication of Routledge and NAEYC.

Hakim, M. S. H. I. (2020). Implementasi Kolaborasi Orang Tua dan Guru Dalam Pelaksanaan Pembelajaran Daring pada PAUD. JIEES : Journal of Islamic Education at Elementary School, 1(1), 26-33. https://doi.org/10.47400/jiees.v1i1.8

Hamdi, A. S., \& E.Bahruddin. (2012). Metodologi Penelitian Kuantitatif Aplikasi Dalam Pendidikan. deepublish.

Handayani, O. D. (2020). Pengembangan Media Pembelajaran PAUD melalui PPG. Jurnal Obsesi : Jurnal Pendidikan Anak Usia Dini, 5(1), 93. https:// doi.org/10.31004/obsesi.v5i1.522

Harper, E., \& Wilson, R. (2020). Work in early childhood education: Protocol of a systematic review. International Journal of Educational Research, 103(February), 101622. https:// doi.org/10.1016/j.ijer.2020.101622

Heong, Y. M., Sern, L. C., Kiong, T. T., \& Binti Mohamad, M. M. (2016). The Role of Higher Order Thinking Skills in Green Skill Development. MATEC Web of Conferences, 70. https:// doi.org/10.1051/matecconf/20167005001

Hewi, L., \& Asnawati, L. (2020). Strategi Pendidik Anak Usia Dini Era Covid-19 dalam Menumbuhkan Kemampuan Berfikir Logis. Jurnal Obsesi : Jurnal Pendidikan Anak Usia Dini, 5(1), 158. https://doi.org/10.31004/obsesi.v5i1.530

Kelley-Quon, L. I. (2018). Surveys: Merging qualitative and quantitative research methods. Seminars in Pediatric Surgery, 27(6), 361-366. https:/ / doi.org/10.1053/j.sempedsurg.2018.10.007 
DOI: 10.31004/obsesi.v5i2.975

Kemendikbud. (2020). Jumlah Data Satuan Pendidikan (Sekolah) Per Kabupaten/Kota: Kab. Jember Berdasarkan Jenis

http://referensi.data.kemdikbud.go.id/index11_sd.php?kode=052400\&level=2

Kementrian Riset Teknologi dan PendidikanTinggi. (2016). Kebijakan Pendidikan Jarak Jauh dan E-Learning di Indonesia Pembelajaran berbasis Teknologi Group growth Individual growth. Ministry of Research, Technology, \& Higher Education, 1-21.

Koehler, M. J., Mishra, P., \& Cain, W. (2013). What is Technological Pedagogical Content Knowledge (TPACK)? Journal of Education, 193(3), 13-19. https://doi.org/10.1177/002205741319300303

Manju, M. A., Candel, M. J. J. M., \& van Breukelen, G. J. P. (2020). Robustness of costeffectiveness analyses of cluster randomized trials assuming bivariate normality against skewed cost data. Computational Statistics \& Data Analysis, 107143. https://doi.org/10.1016/j.csda.2020.107143

Nah, K. O., \& Kwak, J. I. (2011). Child assessment in early childhood education and care settings in South Korea. Asian Social Science, 7(6), 66-78. https://doi.org/10.5539/ass.v7n6p66

Pellegrini, A. D. (2001). Practitioner review: The role of direct observation in the assessment of young children. Journal of Child Psychology and Psychiatry and Allied Disciplines, 42(7), 861-869. https://doi.org/10.1017/S002196300100765X

Rahmawati, D. I., \& Rukiyati, R. (2018). Developing Pop-Up Book Learning Media to Improve Cognitive Ability of Children Aged 4-5 Years. 249(Secret), 60-69. https://doi.org/10.2991/secret-18.2018.10

Singh, V., \& Thurman, A. (2019). How Many Ways Can We Define Online Learning? A Systematic Literature Review of Definitions of Online Learning (1988-2018). American Journal of Distance Education, 33(4), 289-306. https:// doi.org/10.1080/08923647.2019.1663082

Sufiati, V., \& Afifah, S. N. (2019). Peran perencanaan pembelajaran untuk performance mengajar guru pendidikan anak usia dini. Jurnal Pendidikan Anak, 8(1), 48-53. https://doi.org/10.21831/jpa.v8i1.26609

Wijayanti, R. M., Fauziah, P. Y., Anak, P., Dini, U., Yogyakarta, U. N., Sekolah, P. L., \& Yogyakarta, U. N. (2021). Perspektif dan Peran Orangtua dalam Program PJJ Masa Pandemi Covid-19 di PAUD. 5(2), 1304-1312. https:// doi.org/10.31004/obsesi.v5i2.768

Zahro, I. F. (2015). Penilaian dalam Pembelajaran Anak Usia Dini. Tunas Siliwangi.

Zaini, H., \& Dewi, K. (2017). Pentingnya Media Pembelajaran untuk Anak Usia Dini. Raudhatul Athfal: Jurnal Pendidikan Islam Anak Usia Dini, 1(1), 81-96. https://doi.org/10.19109/ra.v1i1.1489 